\title{
Age change in healthcare settings: A reply to Lippert-Rasmussen and Petersen
}

\author{
Abstract
}

Kasper Lippert-Rasmussen and Thomas Søbirk Petersen discuss my 'Moral case for legal age change' in their article 'Age change, official age and fairness in health'. They argue that in important healthcare settings (such as distributing vital organs for dying patients), the state should treat people on the basis of their chronological age because chronological age is a better proxy for what matters from the point of view of justice than adjusted official age. While adjusted legal age should not be used in deciding who gets scarce vital organs, I remind the readers that using chronological age as a proxy is problematic as well. Using age as a proxy could give wrong results and it is better, if possible, for states to use the vital information directly than use age as a proxy.

\section{Introduction}

In 'Moral case for legal age change', I proposed that people who are discriminated against because of their age should be allowed to change their legal age (date of birth) to match it with their biological or emotional age, instead of chronological age, to avoid the discrimination. ${ }^{1}$

Kasper Lippert-Rasmussen and Thomas Søbirk Petersen discuss my proposal and form their own 'official age argument' - which they eventually reject. ${ }^{2}$ They claim that chronological age is a better proxy for what matters from the point of view of justice than adjusted official age, therefore, at least in important healthcare settings (such as distributing vital organs for dying patients), the state should treat citizens based on their chronological rather than their (changed) official ages. The kernel of their idea is this: when deciding whose life we should save (and when we cannot save the lives of all), chronological age should be used as a decision making criteria, because it, allegedly, corresponds well with how many good years one has lived.

While I agree with their idea in general, I remind my critics and readers that in healthcare settings, it is problematic to use proxies in the first place because it might give us wrong results. 


\section{Age change in healthcare settings}

I framed, and defended, ${ }^{3}$ my argument for legal age change as follows (slightly revised in light of criticism from Brassington ${ }^{4}$ ):

P1) Legal age is a cause of severe discrimination for some people whose biological and emotional age do not match their chronological age.

P2) People should be allowed to secure relief from severe discrimination against them unless this has excessive consequences.

P3) Changing a person's legal age would not, in the case of people whose biological and emotional age do not match their chronological age, have excessive consequences.

P4) Changing a person's legal age secures relief from discrimination.

C) People whose biological and emotional age do not match their chronological age should be allowed to change their legal age in order to secure relief from discrimination.

Lippert-Rasmussen and Petersen frame a slightly different argument for the same conclusion and argue against the third premise of it. They claim that if the state were to set healthcare priorities on the basis of adjusted official age (legal age in my argument) it would amount to injustice, and so, age change would have excessive consequences; which makes the argument unsound.

They ask the reader to consider a situation where people have changed their official age and are in need of vital organs.

A number of scarce lifesaving organs must be distributed by a public healthcare system among two groups of patients. Everyone has the official age of 50. However, members of the first group have the chronological age of 70 , while members of the second have the chronological age of 40. Suppose that everyone will enjoy an extra 10 good life years if they receive an organ. Members of the first group have enjoyed 30 more good life years than members of the second group, and that is relevant for who should receive the available organs, justice-wise. Even if a 
member of the second group were to receive an organ, she would still not have enjoyed as many good life years as members of the first group.

Here, chronological age is used as an approximate substitute, an indicator of how many good life years one has lived. I agree, as I think most people would, that it would be unjust to give the vital organs to those who have lived longer. Lippert-Rasmussen and Petersen say that the claim that the members of the first group have enjoyed 30 more good life years than the members of the second group is relevant on a wide range of different accounts of justice in healthcare. If justice requires equalizing bad brute luck across patients, generally, we should give priority to young over old ${ }_{5}^{5}$ if we should give priority to the worse off, the same follows; ${ }^{6}$ and if justice requires that everyone enjoys a sufficient number of good life years, then again chronological age should be taken into account. ${ }^{7}$

Be that as it may, if we have more relevant information available, we might think differently. For instance, consider the following situation.

A vital lifesaving organ must be distributed by a public healthcare system among two patients. Both patients have the chronological age of 50. However, the first person has been in a coma for the past 30 years and just woke up, while the second person has enjoyed 30 good years during that time. Suppose that both would enjoy an extra 10 good life years if they received an organ. The second person has enjoyed 30 more good life years than the first person, and that is relevant for who should receive the available organ, justice-wise. Even if the first person were to receive an organ, she would still not have enjoyed as many good life years as the second person.

Now, when we have more information available (how long the people actually have been conscious and enjoyed their lives) our intuitions, correctly, change. Here, it seems unjust, to deny a lifesaving organ from a person who has just woken up from a coma. Now, the same accounts of justice in healthcare align with this intuition. If justice requires equalizing bad brute luck across patients, we should give priority to the ex-coma patient (supposing she fell into a coma for no fault of her own) over the other 
patient; if we should give priority to the worse off, the same follows; and if justice requires that everyone enjoys a sufficient number of good life years, then again the ex-coma patient should be given priority.

What the case shows is that chronological age does not necessarily correspond well with how many good life years one has lived. ${ }^{i}$ Chronological age, therefore, is not necessarily a good guide when we make decisions on who should get vital organs, although it might be, in general, a better proxy than biological age. Age is often used as a proxy; for example, in insurance, on the labour market, and family, criminal and electoral laws. ${ }^{8}$ Using age as a proxy has both advantages and disadvantages. One disadvantage is that the correspondence between age and the characteristic for which it stands is not often based on evidence but on stereotypes and generalizations. ${ }^{9}$

My point is not to deny the claim that chronological age is a better proxy than biological age in the context of allocating lifesaving transplants. It is. My point is that it is unjust for the state to rely on proxies if more vital and accurate information is available. In the context of allocating scarce organs such information would include, for example, whether the person was wrongfully convicted to prison for years and therefore couldn't live his life fully or whether he has been in a coma for a decade or so. It might even be that someone suffering from many years of clinical depression should receive vital organs, although chronologically younger than others on the organ donation list, because she has enjoyed fewer good life years. ${ }^{\text {ii }}$

In the case that Lippert-Rasmussen and Petersen raised, the reason why one group of people should get priority for the organs over the other is not that they have existed longer but because they have enjoyed more good life years - which often but not always corresponds well with chronological age.

\footnotetext{
${ }^{\mathrm{i}}$ Lippert-Rasmussen and Petersen agree here.

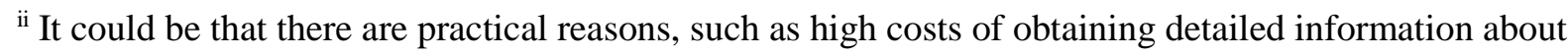
people's lives, that make the use of proxies inevitable.
} 


\section{Conclusion}

I agree with Lippert-Rasmussen and Petersen that in important healthcare settings the state should treat people based on their chronological age rather than official age, when it should treat patients (partly) based on age, but only if the state cannot easily access the more vital information directly (whether one has been in a coma, clinically depressed, wrongfully convicted etc. that has made her unable to enjoy her life).

Lifesaving organs are scarce. If a person gets one, someone else doesn't. But in the job market, where discrimination is perhaps the most pressing, one person's gain is not another's loss. So while legal age change has been hit, it is not down.

${ }^{1}$ Räsänen J. Moral case for legal age change. J Med Ethics 2019;45:461-464.

${ }^{2}$ Lippert-Rasmussen K. \& Petersen T.S. Age change, official age and fairness in health. J Med Ethics. DOI:10.1136/medethics-2020-106078.

${ }^{3}$ Räsänen J. Further defence of legal age change. J Med Ethics 2019;45:471-472.

${ }^{4}$ Brassington I. What a drag it is getting old: A response to Räsänen. J Med Ethics 2019;45:467-468.

${ }^{5}$ Segall S. Health, Luck, and Justice. Princeton, NJ: Princeton University Press 2010.

${ }^{6}$ Parfit D. Equality and priority. In: Mason A., ed. Ideals of Equality. Oxford: Blackwell 1998:1-20.

${ }^{7}$ Harris J. The Value of Life. London: Routledge \& Kegan Paul 1970.

${ }^{8}$ Gosseries, A. What makes age discrimination special? A philosophical look at the ECJ case law. Neth. J. Leg. Philos. 2014;43(1):59-80.

${ }^{9}$ Neugarten B.L. Age Distinctions and Their Social Functions. Chi.-Kent L. Rev. 1981;57(4):822-823. 